\title{
Geopolítica, identidade cultural e a língua espanhola no contexto brasileiro
}

\section{Maria Cláudia de Jesus Machado ${ }^{1}$ \\ Rosa Yokota ${ }^{2}$}

Resumo: Neste trabalho,busca-se refletir sobre a relação entre questões geopolíticas e identitárias e a língua espanhola no contexto brasileiro, bem como mostrar como o entrelaçamento destes elementos pode ser tratado nasala de aula sob uma perspectiva intercultural objetivando ensinar a língua, fomentar o conhecimento de história da América Ibérica e promover a aproximação do aluno brasileiro ao universo dos povos vizinhos.Para tanto, apoiamo-nos no conceito de geopolítica e o associamos às relações de poder para mostrar como estas influenciam o grau de importância atribuído às línguas. Defendemos que a abordagem destes componentes na sala de aula sensibiliza o aluno e o faz entender que o estudo de uma língua estrangeira deve transcender ideologias e contribuir para aproximar culturas, olhar para o mundo sob diferentes perspectivas e evoluir como ser humano.

Palavras-chave: Geopolítica; identidade cultural; comunicação intercultural; língua espanhola; Brasil.

\section{Geopolítica, identidad cultural y la lengua española en el contexto brasileño}

Resumen: En este trabajo, buscamos reflexionar sobre la relación entre las cuestiones geopolíticas e identitarias y la lengua española en el contexto brasileño, además de mostrar como el entrelazamiento de estos elementos pueden ser tratados en el aula desde una perspectiva intercultural con el objetivo de enseñar. el idioma, fomentar el conocimiento de la historia de Iberoamérica y promover el acercamiento del estudiante brasileño al universo de los pueblos vecinos. Para ello, nos apoyamos en el concepto de geopolítica y lo asociamos con las relaciones de poder para mostrar cómo influyen en el grado de importancia atribuido a las lenguas. Argumentamos que el abordaje de estos componentes en el aula sensibiliza al alumno y le hace comprender que el estudio de una lengua extranjera debe trascender las ideologías y contribuir a acercar las culturas, mirar el mundo desde diferentes perspectivas y evolucionar como ser humano.

Palabras clave: Geopolítica; identidad cultural; comunicación intercultural; lengua española; Brasil.

\footnotetext{
${ }^{1}$ Maria Cláudia de Jesus Machado. Doutoranda em Letras pela Universidade Federal de São Carlos, Brasil. E-mail: afamariaclaudia@outlook.com - https://orcid.org/0000-0002-3220-4732

${ }^{2}$ Rosa Yokota. Doutora em Letras. Professora da Universidade Federal de São Carlos, Brasil. E-mail: rosayokota@yahoo.com - https://orcid.org/0000-0002-1672-1430
} 
Geopolitics, cultural identity and the Spanish language in the Brazilian context

Abstract: This paper seeks to reflect on the relationship between geopolitical and identity issues and the Spanish language in the Brazilian context, as well as to showhow the intertwining of these elements can be treated in the Spanish language class from an intercultural perspective aiming, at the same time, to teach the language, foster the knowledge of the history of Iberian America and promote the approximation of the Brazilian student to the universe of neighboring peoples. To this end, we rely on the concept of geopolitics and associate it with power relations to show how they influence the degree of importance attributed to languages. We argue that the approach of these components in the classroom sensitizes the student and makes him understand that the study of a foreign language must transcend ideologies and contribute to bringing cultures together, looking at the world from different perspectives and evolving as a human being.

Keywords: Geopolitics; cultural identity; intercultural communication; Spanish language; Brazil.

\section{Geopolítica, identidade cultural e a língua espanhola no contexto brasileiro}

\section{Introdução}

No presente trabalho buscamos destacar o entrelaçamento entre questões geopolíticas, identitárias e a presença da língua espanhola no contexto brasileiro, uma vez que tanto - Brasil quanto os países hispanofalantes foram colonizados por povos ibéricos e compartilham, em muitos aspectos, características adquiridas ao longo e após o processo de colonização. No que tange ao ensino de língua estrangeira no contexto brasileiro, as questões geopolíticas e identitárias acabam interferindo no grau de importância atribuído às línguas e na sua escolha para compor a grade curricular dos cursos nas instituições de ensino. Desse modo, a escolha não gira em torno apenas do fator instrumental, ou seja, de sua finalidade comunicativa.

Iniciamos este trabalho abordando alguns fatores de caráter geopolítico, histórico e social compartilhados que acabaram incutindo nos povos ibero-americanos traços culturais comuns ou, até mesmo, uma tênue confluência de identidades, visto que, apesar da proximidade geográfica, social e histórica, nota-se que a região não está plenamente integrada, unida, interdependente, com convergência de interesses e objetivos, e confiança recíproca. Posteriormente, vinculado às questões identitárias, tratamos as representações socioculturais do outro e propomos o diálogo intercultural como forma de aproximação entre o 
Brasil e os povos hispano-americanos. Finalizamos com uma proposta para a aula de língua espanhola baseada em conteúdos históricos, geográficos, políticos e culturais relacionados ao contexto sul-americano, e em uma abordagem intercultural. Entendemos que não é possível dissociar o espaço da sala de aula de língua estrangeira do espaço sociopolítico externo, dado que ela própria se converte em um espaço sociopolítico.

Um professor de língua espanhola que tenha ciência da função política do ensino desta língua no Brasil e de que este tem relação com a formação para a cidadania, que seja sensível à abordagem intercultural e que tenha conhecimento das culturas que compõem a América Ibérica, de sua história, de sua geografia e, inclusive, de sua literatura,tanto hispano-americana quanto brasileira, visto que muitas de suas obras ajudam a compreender aspectos históricos e sociais que envolvem essa região,poderá, ao mesmo tempo, ensinar a língua, fomentar o conhecimento de história e promover a aproximação do aluno brasileiro à realidade dos povos vizinhos. Quando fazemos menção à história, referimo- nos a toda a trajetória desde a presença das civilizações précolombianas no território, passando pelo encontro dos colonizadores com os nativos e os choques culturais dele derivados, pela formação da sociedade latino-americana, pelas guerras de independência e suas motivações, pela intervenção estrangeira, e por quaisquer fatos de ordem política, econômica e social que marcaram e marcam essa trajetória e contribuíram e contribuem para a formação da nossa identidade ou identidades latino-americanas.

Destacamos que o professor como interculturalista colabora com a construção de pontes que dão acesso à cultura do outro. Segundo Matos (2018, p. 21) "a perspectiva intercultural pressupõe uma série de ações em prol do reconhecimento da diversidade que nos constitui e do combate a atitudes de discriminação para com o outro". 
Aspectos geopolíticos, sociais e históricos da América lbérica e as relações de poder

Com o intuito de apresentar o entrelaçamento entre questões linguísticas, geopolíticas e de poder, iniciamos com 0 conceito de Geopolítica, pois a palavra está associada aos assuntos que envolvem relações internacionais, acordos diplomáticos e todo tipo de conflito entre países, culturas ou disputas territoriais. $O$ conceito formulado por Mattos (2002, p. 33) resume o pensamento: "Geopolítica é a Política aplicada aos espaços geográficos sob a inspiração da experiência histórica".

A Geopolítica tem caráter dinâmico, pois considera-se a operacionalidade do homem no espaço geográfico para o seu uso político, cujo objetivo é a geração de poder, que, por sua vez, pode dar um novo direcionamento ao destino das nações, contribuindo para a construção ou reconstrução da história.Portanto,a exploração do espaço geográfico é a base de sustentação da geopolítica, uma vez que esta resulta da interação da geografia, da história e da política, e está relacionada ao poder do Estado.
Se fizermos um percurso pela história, veremos que ela está inteiramente marcada pela apoderação de espaços que foram transformados pela ação de conquistadores. É preciso notar que o fato de delimitar parcelas, de marcá-las, cercá-las também envolve a questão da alteridade, ou seja, as relações com os indivíduos ou grupos que aí se inserem. Essa interação modifica tanto as relações com a natureza quanto as relações sociais, e os atores se automodificam também. A territorialidade também funciona como um instrumento para comunicar um ideário: a preservação ou a construção de uma identidade.

Após a chegada dos povos ibéricos no continente americano, iniciou-se uma reconfiguração geopolítica, pois os tratados de divisão da América, como o de Tordesilhas (Figura 1), demarcaram as fronteiras entre terras espanholas e portuguesas. 
Figura 1.Mapa do Tratado de Tordesilhas

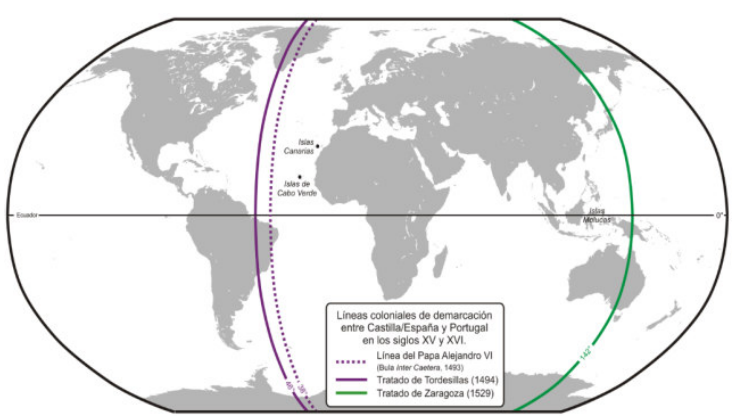

Fonte:https://commons.wikimedia.org/wiki/File: Spain_and_Portugal.png

Os espanhóis criaram um império que se estendia desde o sul do que é atualmente Estados Unidos até a Terra do Fogo. Invadiram e colonizaram territórios extensos, fundaram cidades, dividiram terras, construíram vias de comunicação, pontes e portos; desenvolveram a agricultura, a produção de manufaturas e o comércio e exploraram os recursos minerais; mataram e subjugaram os povos originários sobreviventes e importaram escravos africanos (QUESADA, 2001). Houve a divisão tripartida a serviço do poder: a população, o território e os recursos, o que não foi diferente no Brasil, considerando que o poder é inerente a toda relação.

Após 0 processo de independência, houve mudanças significativas na reconfiguração geopolítica do território ibero- americano: os vice-reinos foram divididos, tornaram-se Estados e adotaram o sistema republicano de governo, ao contrário do Brasil que, após sua independência em 1822, manteve a sua unidade e adotou a monarquia constitucional (Figura 2 e Figura 3).

Figura 2. Mapa da América Ibérica antes da independência

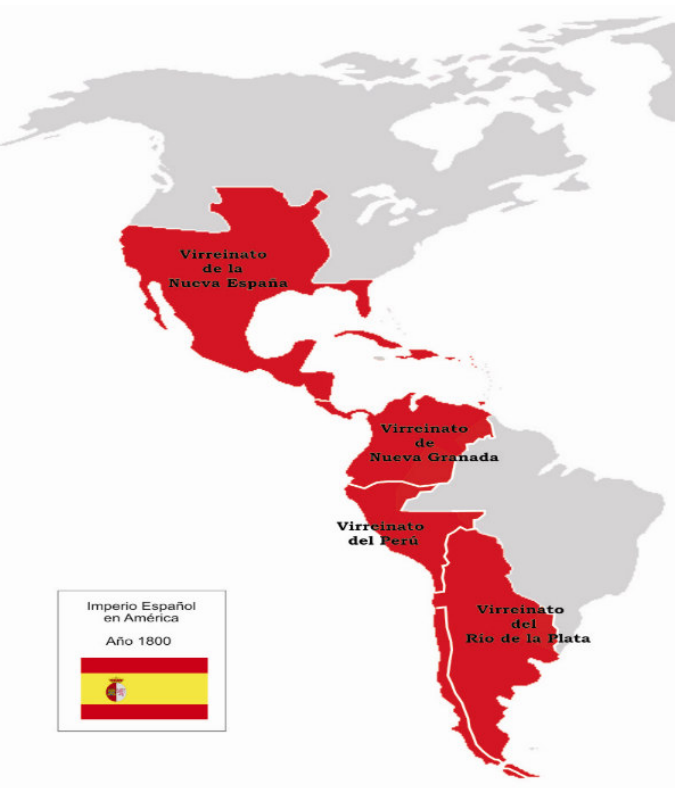

Fonte:

commons.wikimedia.org/wiki/File:Imperio_Esp añol_America_1800.png 
Figura 3.Mapa da América Ibérica após a independência

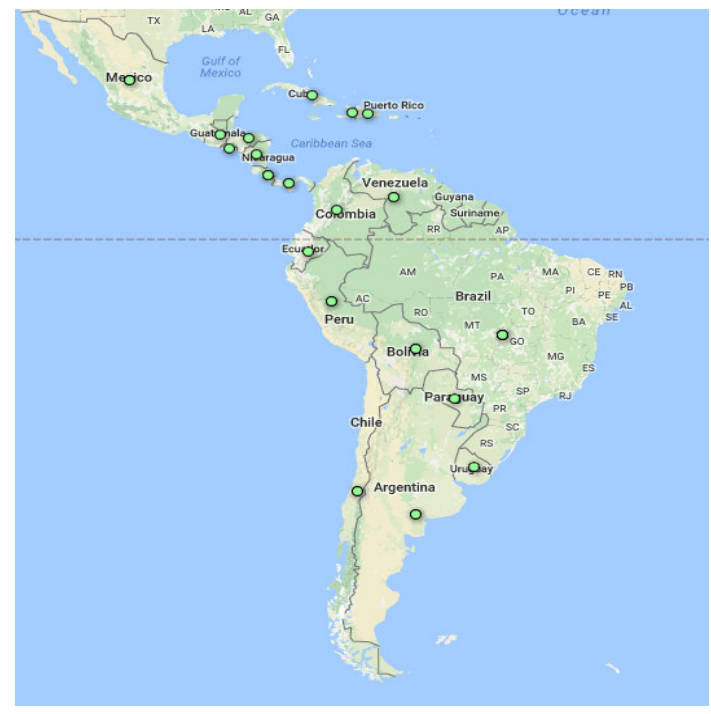

Fonte:

openei.org/wiki/File:Mapa_de_Centros_de_En ergías_Renovables_en_Latinoamérica.png

A independência da América Hispânica e da América Portuguesa, por um lado, favoreceu financeiramente e politicamente a aristocracia e não contribuiu para a diminuição das desigualdades e injustiças sociais. As aspirações regionalistas não tardaram em promover a desagregação da grande nação.

Os países hispano-americanos, cuja história se parece muito à brasileira, compartilham aspectos como a conquista, a colonização, o intervencionismo estrangeiro, os regimes políticos, a luta pelo desenvolvimento, a proximidade geográfica e a abundância de recursos naturais. No entanto, muito tempo se passou desde a independência e o ideal de uma aproximação de fato entre ambas as partes ainda não se concretizou. O distanciamento que se produziu entre o Brasil e os demais países da América do Sul desde a época colonial, resultante das demarcações territoriais, da diferença entre as línguas maternas, entre outros fatores, pode ter contribuído para a crença em identidades divergentes. A América Ibérica e, em uma dimensão menor, o Brasil e seus vizinhos hispano-americanos parecem formar um grande quebra-cabeça cujas peças ainda não se encaixaram efetivamente apesar das tentativas já ocorridas de integração, principalmente no plano econômico com a formação de blocos.Aparentam ser dois mundos abraçados no plano geográfico, e histórico, mas um tanto afastados no plano identitário. Essa desagregação se reflete no plano linguístico, pois assistimos à desvalorização do ensino da língua espanhola no Brasil, principalmente pela entrada em vigor da Lei $n^{0} 13415$, de 16 de fevereiro de 2017 (BRASIL, 2017) pela qual a obrigatoriedade do ensino de Língua Estrangeira Moderna 
passou a restringir-se à Língua Inglesa. Tal fato deixa claro 0 entrelaçamento entre as questões geopolíticas, identitárias e linguísticas. Altera-se a política de governo no Brasil, ocorre um afastamento dos países hispano-americanos e, consequentemente, altera-se a política linguística também ${ }^{3}$.Uma política que não defende o plurilinguismo é uma política que defende 0 isolamento, anula as diferenças culturais e impõe uma única racionalidade, pois a língua é vetor da cultura de um povo e um dos elementos que constituem sua identidade.

Conforme o Relatório Mundial da UNESCO - Investir na Diversidade Cultural e no Diálogo Intercultural (2009, p. 12):

As línguas são os vetores das nossas experiências, dos nossos contextos intelectuais e culturais, dos nossos modos de relacionamento com os grupos humanos, com os nossos sistemas de valores, com os nossos códigos sociais e sentimentos de pertencimento, tanto no plano coletivo como individual.[...] as línguas não são somente um meio de comunicação, mas representam a própria estrutura das expressões culturais e são portadoras de identidade, valores e concepções de mundo.

\footnotetext{
${ }^{3}$ Cf. Rodrigues (2010) para informações a respeito das políticas linguísticas para o ensino de espanhol no Brasil a partir da primeira metade do século XX.
}

$\mathrm{Na}$ nova ordem, não há interesse em que os modelos culturais e as identidades locais se fortaleçam, pois estes se opõem à ideia do homogêneo e constituem uma ameaça, visto que, segundo Raffestin (1993), o ganho de poder está vinculado ao ganho de espaço. Portanto, a língua como vetor de cultura e componente da identidade de um povo também é um instrumento de poder. Conforme Raffestin (1993), o poder é parte intrínseca de toda relação. Uma das proposições de Foucault (1988 apud RAFFESTIN, 1993) é que as relações de poder não estão em posição de exterioridade no que diz respeito a outros tipos de relações como as econômicas, de conhecimento, sociais, sexuais etc., mas Ihes são imanentes.

Paradoxalmente, ao mesmo tempo que a nova ordem global fomenta a homogeneização dos modelos culturais, há a valorização dos elementos locais frente à interposição dos globais. Para Santos (2006, p. 231), "cada lugar é, ao mesmo tempo, objeto de uma razão global e de uma razão local, convivendo dialeticamente". As ações locais constituem, muitas vezes, uma 
forma de resistência. Outro paradoxo é que com a globalização as possibilidades de contato intercultural aumentaram permitindo mais oportunidades de aproximação entre os povos, tanto física quanto virtualmente, dado que as redes de comunicação encurtaram ou eliminaram as distâncias, embora nem todos tenham acesso a esses benefícios. Aproximar-se do outro, conhecê-lo é um pré-requisito para o estabelecimento do diálogo intercultural. Para Guigoü (1995 apud SANTOS, 2006, p. 216), "a aproximação pode criar a solidariedade, laços culturais e, desse modo, a identidade". É uma oportunidade de descobrir as semelhanças, conhecer as diferenças, compreendê-las, aprender com elas e rever antigas crenças. Desse modo, a alteridade é uma condição que pode ser verificada quando há interação entre o "eu" e o "outro", ao reconhecermos que a nossa cultura, assim como a dos países influentes são culturas possíveis entre tantas outras e não as únicas.

Não obstante, em muitos casos, uma aproximação de fato e a criação de uma identidade depende do rompimento de barreiras. As representações socioculturais que um indivíduo tem de uma língua ou cultura constituem uma destas barreiras que se apresentam na forma de estereótipos e preconceitos. Na seção seguinte, trataremos das representações socioculturais do outro.

\section{As representações socioculturais do outro}

O status que um sujeito atribui a uma língua estrangeira está condicionado, em grande parte, à representação que ele tem da cultura veiculada por ela, uma vez que ele tende a considerar a língua como elemento de identificação do indivíduo como pertencente a uma nação com um sistema de valores, costumes e tradições culturais, ignorando a ideia de que dentro de um território identificado como uma nação podem coexistir várias línguas e culturas.

Uma das formas de representação são os estereótipos, definidos por Allport (1954 apud DERVIN, 2014) e Bar Tal (1996 apud DERVIN, 2014) como um conjunto de crenças sobre as características de uma categoria social de pessoas 
(traços de personalidade, atributos, intenções, descrições comportamentais), formados e aprendidos dentro dos próprios grupos sociais e reforçados, sobretudo, pelos meios de comunicação. A sua função é diferenciar grupos, mostrando, inclusive, a superioridade de uns sobre outros, providos de aspectos ideológicos.

Para exemplificar, citamos Kumaravadivelu (2003) que aborda a questão dos estereótipos associados aos estudantes asiáticos no contexto acadêmico norte-americano. Ele critica a ideia de homogeneização cultural, pois tanto chineses quanto indianos, japoneses, coreanos e vietnamitas são colocados no mesmo "cesto cultural" denominado "asiático", apesar de diferenças aparentes entre eles.

Além dos estereótipos, Dervin (2014) apresenta outra forma de representação social, othering, relacionada principalmente à raça, à etnia e ao sexo feminino.O autor define-a como a "objetificação de uma pessoa ou grupo" ou "a criação do outro". Ignora-se a subjetividade e a complexidade do indivíduo;leva as pessoas a diferenciarem o seu grupo de outro grupo e o eu do outro, de forma que reforce e proteja o eu.

Observando os diferentes contextos sociais, nota-se que são abundantes as representações sociais na forma de estereótipos ou othering. Citamos como exemplo o uso dos termos "os latinos", "as mulheres"em frases que expressam um sentido pejorativo podendo em certos contextos serem caracterizadas como preconceito.

Citamos Paraquett (2018) que, ao fazer referência à criação do termo América Latina, menciona o movimento "panlatinismo" surgido no século XIX,relacionado ao desejo hegemônico da França sobre a região. Segundo a autora, "essa pretensa hegemonia estava relacionada à nascente dominação norte-americana e à, então, hegemonia da Inglaterra" (PARAQUETT, 2018, p. 77). A ideologia norte-americana acabou se sobrepondo no território e dela derivou-se a imagem negativa dos hispano-americanos nos Estados Unidos. Para ilustrar, transcrevemos um trecho de Figueiredo (2010 apud PARAQUETT, 2018, p. 78):

[...] a imagem negativa dos hispanoamericanos nos Estados Unidos foi construída, até meados do século $\mathrm{XIX}$, em torno dos termos 
catolicismo, indolência, ignorância e falta de iniciativa, que se oporiam à imagem que os norte-americanos faziam de si próprios, protestantes, trabalhadores e empreendedores.

Com relação às questões raciais e étnicas, observa-se que os grupos mais atingidos são indígenas, mestiços, negros e imigrantes procedentes de países subdesenvolvidos ou em guerra. Nestes casos, a fronteira entre 0 estereótipo e o preconceito é quase inexistente.

Cabe questionar se essas representações não estariam vinculadas a uma concepção etnocêntrica, conservadora,hierarquizada impositiva de cultura conforme ocorreu com a colonização da América Ibérica. A cultura da metrópole tinha a missão de "salvar o selvagem em estado de barbárie", de "cultivar a sua alma", usando a terminologia de Bauman (2013, p.13,15). Segundo o autor, a teoria cultural evolucionista promovia o mundo "desenvolvido" ao status de perfeição inquestionável, a ser imitada e ambicionada, mais cedo ou mais tarde, pelo restante do planeta. Acrescenta que, na busca por esse objetivo, o resto do mundo deveria ser ativamente ajudado e, em caso de resistência, coagido. Estabelece-se uma relação de dominador e dominado.

Segundo Salomão (2015), essa visão etnocêntrica de cultura tem suas origens no século XVI, quando passou a designar o desenvolvimento de uma faculdade, como, por exemplo, 'cultura das artes', 'culturas das ciências'. Ainda, segundo a autora, no século XVIII, este sentido passou a refletir a ideia iluminista de cultura como "a soma dos saberes acumulados e transmitidos pela humanidade". Assim sendo, a "cultura" era própria do Homem, distinguia povos e classes e estava associada às ideias de progresso, de evolução, de educação, de razão, assemelhando-se à palavra "civilização" (CUCHE, 2002 apud SALOMÃO, 2015, p. 364).

Julgamos conveniente citar como exemplo, a obra literária hispano-americana Facundo ou Civilização e Barbárie, escrita em 1845 pelo escritor argentino Domingo Faustino Sarmiento. $\mathrm{Na}$ obra, a natureza selvagem condiciona o caráter e as possibilidades da vida em sociedade. Neste caso, a natureza do pampa argentino opõe-se ao ambiente 
da cidade, da mesma forma que a barbárie opõe-se à civilização, e a vida social argentina antes do processo de independência era formada pela classe espanhola, europeia, branca, denominada civilizada e outra americana, mestiça, quase indígena, denominada bárbara.

Ante 0 exposto faz-se necessário pesquisar as condições sociais, políticas, econômicas e históricas que levaram à criação das representações e verificar quais são os canais utilizados para a sua transmissão (sociais, políticos, culturais, educacionais), bem como a ideologia oculta a estas transmissões.

No âmbito da Linguística, os estudos sobre comunicação intercultural contribuem para lançar luz sobre a questão.

\section{A comunicação intercultural como} forma de aproximação

Não é possível admitir a ideia do determinismo geográfico ou biológico para tratar de questões culturais, ou seja, crer que o indivíduo é um ser passivo frente à ação das forças naturais ou características biológicas. As forças decisivas estão na própria cultura e na história da cultura, pois esta é um construto dinâmico. Ela é o resultado de toda experiência histórica das gerações anteriores. Somando-se a isso, é preciso considerar que o mundo, protagonizado por atores sociais, está em constante evolução; as transformações no ambiente ocorrem e provocam um processo de mudanças adaptativas. Os indivíduos têm a capacidade de questionar os seus próprios hábitos e modificá-los; portanto, os sistemas culturais estão em processo contínuo de modificação devido às forças internas e ao contato com outros sistemas culturais, pois os povos não estão isolados. Isso nos leva a considerar que a compreensão da cultura exige reflexão sobre os diversos povos, sociedades e grupos humanos, que hoje, mais do que em qualquer outro momento, lhes são oferecidas maiores oportunidades de interação, seja pelo contato físico ou pelos meios de comunicação social.

Segundo a teoria construtivista, a convivência social modifica os agentes e os Estados não podem ser considerados como verdades exógenas; as ideias e normas possuem um papel fundamental tanto na constituição da realidade e dos 
agentes, quanto na definição de identidades e interesses, pois exercem um efeito constitutivo nos atores (WENDT, 1999). Com relação ao conhecimento do outro, é por meio das trocas sociais e culturais que as aproximações são fomentadas, o que pode conduzir à produção de novos conhecimentos, novas subjetividades, novas identidades e novos interesses.

O construtivismo é indissociável da questão da alteridade: o homem, como ser social, existe a partir da visão e do contato com o outro ou outros, a coletividade.

Acreditamos que a aproximação entre os países da região passa pela construção de uma rede de comunicação que ajude a diminuir as distâncias entre nossos povos e culturas: acesso recíproco aos canais de rádio e de televisão dos países sulamericanos, mais acesso por parte dos brasileiros aos filmes e ao mercado editorial em espanhol e viceversa, incentivo ao turismo na região, participação em competições esportivas. A criação de espaços culturais para exposições, exibições de filmes, apresentações de música e dança, bem como o estudo do patrimônio cultural ibero-americano, criação de itinerários culturais, fóruns de diálogo intercultural também são exemplos de iniciativas que promovem a comunicação intercultural. No contexto educacional, palestras, cursos sobre temas relacionados à América Ibérica, o intercâmbio de estudantes universitários, o estudo das línguas portuguesa, espanhola e, inclusive, das línguas indígenas promoveriam a descoberta de outras culturas e a abertura à alteridade, e o ensino de História, com base em uma abordagem crítica, contribuiria para elucidar fatos que foram omitidos ou contados com base em uma perspectiva única.

A aproximação estabelecimento de diálogos interculturais, ou seja, de uma troca de ideias aberta e respeitadora são fontes de riquezas, de informações e de experiências, que poderiam contribuir para a reflexão sobre estereótipos e preconceito. Tudo isso resultaria em maior coesão social e na consequente criação de uma consciência integracionista.

De todos os contextos que facilitam o desenvolvimento da competência intercultural, acreditamos que o contexto escolar desempenha 
um papel fundamental para alcançar esse objetivo, pois propicia ao aluno uma educação voltada para uma aprendizagem mais efetiva e para a sua própria transformação. Paulo Freire (1983) faz referência a uma educação que coloque o indivíduo em uma postura de reflexão e de autorreflexão sobre seu tempo e seu espaço. Acreditamos que, em se tratando do ensino de línguas, uma abordagem intercultural ou inclusive multicultural pode contribuir à adoção de tal postura, uma vez que o aluno irá refletir sobre o tempo e o espaço do outro.Essa postura poderá contribuir a eliminar atitudes negativas para com a comunidade ou comunidades da língua estrangeira e, até mesmo, para com a sua própria, fazendo com que ambas sejam olhadas com mais respeito.Desse modo, é necessário que o professor assuma o perfil de interculturalista que, segundo Serrani (2005), corresponde ao de um docente de língua materna ou estrangeira apto para realizar práticas de mediação sociocultural, contemplando os conflitos identitários e contradições sociais na linguagem da sala de aula.Há de se desprover de todo e qualquer estereótipo ou superioridade já construídos. Fiorin (2014) esclarece que, muitas vezes, a diferença é convertida em inferioridade, sendo a língua do outro classificada como ridícula, feia e grosseira, o mesmo ocorrendo com a cultura ou culturas dos povos que a falam.

Coracini (2003) coloca a importância de se considerar as representações que os sujeitos têm da língua e da cultura estrangeira para a compreensão da identidade dos mesmos e das implicações para o processo de ensino-aprendizagem. Como os sujeitos veem a língua e a cultura estrangeira, que imagens têm da língua, do país ou países onde é falada, dos povos que a falam, e quais são as consequências para a constituição da identidade do sujeito.

Deriva-se daí que aprender uma língua estrangeira e interagir nessa língua envolve uma segunda dimensão psíquica - a do sujeito com a sua língua e cultura -, pois não se pode ignorar a história do aprendiz com a sua língua materna, com o seu país, com os membros de sua comunidade, e o contato com o mundo do outro implica, muitas vezes, a necessidade do rompimento de barreiras, de 
mudanças de paradigmas, o que gera desconforto e resistência.

Iglesias Casal (2003) apresenta três dimensões às quais devemos nos atentar, já que muitos professores ensinam cultura como algo invariável e estático:

1. Crenças e atitudes: trabalhar de maneira crítica o conceito de cultura e acerca de preconceitos, discriminação, etnocentrismo e estereótipos.

2. Conhecimentos: capacidade de conhecer nossa própria perspectiva do mundo, nossa identidade cultural, mesmo não sendo unitária e estável.

3. Habilidades: capacidades específicas, técnicas de intervenção e as estratégias para trabalhar com grupos de distintas culturas, para poder estabelecer um diálogo crítico e autocrítico.

Com base no exposto, concluise que não se desestrangeiriza uma língua apenas com a decodificação do sistema linguístico. O trabalho com $\mathrm{O}$ componente intercultural em sala de aula poderá contribuir para a quebra de barreiras entre culturas, para uma maior motivação e aceitação do estudo da língua estrangeira. Considerando o ensino e a aprendizagem da língua espanhola no contexto brasileiro, o professor pode contribuir estimulando a curiosidade dos alunos para conhecer melhor os países vizinhos, seu território, sua sociedade, sua história e ver o que eles têm a nos dizer. Nosso pensamento vai ao encontro dos dizeres de Rajagopalan (2009, p. 17):

os métodos e as técnicas a serem adotados para o ensino de línguas estrangeiras precisam estar atentos às especificidades sociopolíticas do país em questão, particularmente as coordenadas geopolíticas que, em larga medida, influenciam as atitudes dos cidadãos em relação às línguas em questão, como também as políticas linguísticas adotadas pelos governos.

Com o intuito de trabalhar conteúdos históricos, geográficos, políticos e culturais relacionados ao contexto sul-americano com base em uma abordagem intercultural, apresentamos, a seguir, uma atividade para a sala de aula de língua espanhola 4 .

\footnotetext{
${ }^{4} \mathrm{~A}$ atividade foi aplicada na aula de língua espanhola em um contexto militar e, apesar de não ter sido feita uma coleta de dados com fins de pesquisa, subjetivamente, foi possível avaliar que houve uma reflexão que superou o que se costuma ter na aula convencional no contexto em que foi aplicada.
} 
Proposta para desenvolver a comunicação intercultural na aula de língua espanhola

No tocante ao ensino da língua espanhola, acreditamos que uma abordagem pautada no componente intercultural, por meio do uso de conteúdos históricos, geográficos e culturais relacionados ao contexto sulamericano, poderá sensibilizar os alunos ao estudo da citada língua, com o intuito de motivá-los, despertar-lhes a curiosidade e levá-los a entender as razões pelas quais a estudam, ou seja, mobilizá-los para uma mudança de atitude mais positiva com relação à língua espanhola e às culturas hispânicas. A análise crítica de fatos históricos, o trabalho com conceitos como território, Estado e nação, com as semelhanças culturais, bem como com as diferenças, oferecem aos alunos a oportunidade de refletirem e começarem a desenvolver, durante o processo de aprendizagem, uma noção mais precisa do espaço que ocupam e, inclusive, um sentimento de identificação com a língua $e$ as culturas dos nossos vizinhos, sentimento que contribua a promover uma maior aproximação entre as partes e, inclusive, entender a posição que a região ocupa no mundo e, numa dimensão menor, a posição que ele, como cidadão, ocupa no seu país.

Com relação às práticas em sala de aula, acreditamos que o cinema, entre outras formas de arte,constitui um auxílio de grande importância e eficácia ao desenvolvimento da competência intercultural, uma vez que é produto da cultura humana, ato de comunicação que revela a identidade cultural de um povo, instrumento que permite analisar a realidade, embora os aspectos reais, muitas vezes, se fundam com a ficção. Por meio do cinema, o indivíduo pode fazer uma viagem pelo presente e passado de um povo, conhecer a sua história, sua sociedade, seus costumes, o pensamento de uma época e estabelecer conexões com o momento atual.

No caso da América Ibérica, muitas obras enfocam a problemática político-social do território denunciando a marginalização das minorias étnicoculturais, principalmente das populações indígenas, a exclusão social, o militarismo, a violência política, os abusos históricos cometidos pelas potências colonizadoras e o intervencionismo 
estrangeiro no território. A mestiçagem

e a fusão de culturas também constituem matéria-prima para a criação. Tais obras, por sua vez, constituem um material valioso para trabalhar a competência intercultural na sala de aula, uma vez que é possível estabelecer pontes culturais entre a América Hispânica e o Brasil e entender a realidade atual, pelo fato de compartilharem muitos aspectos históricos. Isso possibilitaria o despertar da consciência crítica, um maior entendimento e uma maior aproximação entre ambos.

Sugerimos o uso do filme "Diários de Motocicleta", baseado nos livros "Notas de Viaje", de Ernesto Guevara, e "Con el Che por Sudamérica", de Alberto Granado, que conta a viagem dos dois amigos, iniciada em 1952, ao longo de grande parte da América do Sul, uma viagem que começou como uma aventura, mas que acabou resultando em uma tomada de consciência por parte de Ernesto a respeito da realidade latinoamericana.

O objetivo da atividade é levar o aluno brasileiro a conhecer um pouco mais a cultura ou as culturas hispanoamericanas, observar de forma crítica as semelhanças e diferenças com relação à cultura ou às culturas brasileiras, e refletir sobre a sua própria identidade cultural e dos povos hispano-americanos. Todo esse processo deverá ser mediado pelo professor.

Previamente, poderá indagar os alunos a respeito do protagonista, das características geográficas e históricas do território hispano-americano, fazendo-lhes recordar as aulas de história e de geografia e usar o seu próprio conhecimento de mundo, bem como fazer-lhes refletir sobre o título. O professor chamará a atenção dos alunos para o enredo, personagens, espaço, tempo e as relações de poder presentes no filme.

Após a exibição, o professor poderá distribuir aos alunos, divididos em grupos, uma lista de tópicos como: climas, paisagens, primeiros habitantes, colonização, mestiçagem, independência, nacionalidades, classes sociais, ritmos musicais, alimentos, idioma, política, economia, entre outros, para que reflitam, associem com passagens do filme e façam uma relação com o contexto brasileiro. Com certeza, encontrarão muitas características comuns, o que 
Ihes possibilitará estabelecer uma ponte entre ambas as culturas. Espera-se, também que estabeleçam um vínculo entre seu passado e seu presente, que vejam se as questões políticas e sociais abordadas no filme fazem parte apenas do passado ou se continuam no presente, e que reflitam sobre a divisão da América Hispânica em pequenas nações.

Com relação ao idioma espanhol, o professor deve levá-los a perceber que não existe apenas a variedade peninsular, da mesma forma que não existe apenas uma variedade do português. Sugere-se, também, que os leve a questionar a crença em superioridade linguística, perguntandoIhes quais motivos fazem um indivíduo pensar que existam línguas melhores, piores, mais ou menos importantes, dado que a língua é um bem cultural. Nesse ponto, o professor poderá tocar na questão do poder, dos estereótipos e preconceitos e relacioná-los com a citada crença; discutir as possíveis origens e formas de transmissão.

Como atividades finais sugerese uma pesquisa a respeito de Machu Picchu, declarada Patrimônio Cultural da Humanidade, assim como de outros locais na América Latina declarados
Patrimônio Cultural e Natural da Humanidade. Também, que os alunos pesquisem sobre temas de atualidades na América Latina para apresentar na aula e acrescentem seus próprios pontos de vista a respeito. Devem observar se há acontecimentos comuns aos diferentes países e refletir se as causas podem estar conectadas ao passado, a apenas fatores internos ou, inclusive, a fatores externos à região. Sugere-se, também, discutir formas de fomentar o diálogo entre culturas.

A proposta apresentada, pautada numa abordagem intercultural, por meio do uso de conteúdos históricos, geográficos, políticos e culturais relacionados ao contexto sul-americano, compôs-se de uma atividade principal e duas atividades complementares dela derivadas. Acreditamos que este tipo de prática, além de promover uma maior compreensão das culturas em questão, também aumentará a motivação dos alunos brasileiros para o estudo da língua espanhola e promoverá uma possível mudança de atitude. 


\section{Conclusão}

O desenvolvimento do presente trabalho mostra como o ensino e a aprendizagem de uma língua estrangeira estão vinculados às questões geopolíticas e identitárias. Portanto, resulta impossível isolar esse processo do contexto no qual ocorre. A escolha da língua ou das línguas que compõem a grade curricular das instituições de ensino são determinadas pela política de governo que, por sua vez, é influenciada pelas ideologias assim como pela conjuntura política e econômica do momento. Dessa forma, acaba-se atribuindo maior poder a uma língua em detrimento de outra. A língua à qual se atribui um valor maior será aquela de um país que exerce influência sobre os demais, geralmente em nível global.No caso do ensino de espanhol no contexto brasileiro, percebe-se a sua desvalorização, apesar da proximidade geográfica entre o Brasil e as nações hispano-americanas e de uma história compartilhada.Seria a desvalorização resultado da crença de que não é necessário aprender uma língua de países pouco influentes em nível global? Ou seria um sentimento de superioridade por parte dos brasileiros

com relação aos seus vizinhos? Nesse sentido, cabe indagar qual é a representação social dos povos hispânicos para os brasileiros.

Tendo em vista os aspectos observados, cabe ao professor mostrar ao aluno que o estudo de uma língua estrangeira transcende ideologias, visto que o conhecimento de idiomas contribui para a sua formação humanística, promove a aproximação entre culturas, contribui para a desconstrução das representações socioculturais negativas, amplia a sua visão de mundo, faz tomar consciência do pluralismo cultural e linguístico e valorizar a diversidade. Portanto, uma língua não exclui a outra.

Com base no exposto, concluise que ensinar espanhol no contexto brasileiro é um desafio, pois o aluno de língua espanhola precisa ser continuamente sensibilizado e motivado. Acreditamos que uma maneira de fazê-lo seria colocá-lo em contato com a pluralidade cultural do mundo hispânico e suas manifestações, resgatar a história da América lbérica na sala de aula, bem como a sua identidade ou identidades culturais e abordar o conteúdo sob 
uma perspectiva intercultural, pois a quebra de barreiras começa a ocorrer quando conhecemos o outro, nos familiarizamos com a sua história e com os valores de sua cultura e percebemos nossas semelhanças e diferenças.

\section{Referências bibliográficas}

BAUMAN, Zygmunt. A cultura no mundo líquido moderno. Rio de Janeiro: Zahar, 2013.

BRASIL. Lei $n^{\circ}$ 13.415. Dispõe sobre a reforma do ensino médio. Diário Oficial da República Federativa do Brasil. Seção 1. Brasília,17 fev. 2017. Disponívelem:http://pesquisa.in.gov.br/ imprensa/jsp/visualiza/index.jsp?jornal $=1 \&$ pagina $=1 \&$ data $=17 / 02 / 2017$.

Acesso em: 04 jun. 2020.

CORACINI, María José. A celebração do outro. In: CORACINI, Maria José (org.). Identidade e discurso: (des)construindo subjetividades. Campinas: Editora da UNICAMP ; Chapecó: Argos, 2003. p. 201-220.

DERVIN, Fred. Cultural identity, representation and othering. In: JACKSON, Jane. The Routledge Handbook of Language and Intercultural Communication. New York: Routledge, 2014. p. 181-194.

DIARIOS DE MOTOCICLETA. Direção: Walter Salles. Produção: South Fork Pictures e Tu Vas Voir Productions. Estados Unidos, Argentina, Brasil, Peru, Chile: Buena Vista International, 2004. 2h06min.

FIORIN, José Luiz. As relações de poder entre as línguas e a dimensão política de seu uso. In: BASTOS,
Neusa Barbosa (org.). Língua portuguesa e lusofonia. São Paulo: EDUC, 2014. p. 51-66.

FREIRE, Paulo. Educação como prática da liberdade. Rio de Janeiro: Paz e Terra, 1986.

IGLESIAS

CASAL, Isabel. Construyendo la competencia intercultural: sobre creencias, conocimientos y destrezas. Carabela, n. 54, p. 5-28, 2003.

KUMARAVADIVELU, Bala. Problematizing Cultural Stereotypes. Tesol Quarterly, vol. 37 n. 4, p. 709719, 2003.

MATOS, Doris. O professor de espanhol como agente intercultural e as articulações necessárias na elaboração de materiais didáticos. In: MATOS, Doris; PARAQUETT, Márcia (orgs.). Interculturalidade e identidades: formação de professores de espanhol. Salvador: EDUFBA, 2018. p. 17-33.

MATTOS, Carlos de Meira. Geopolítica e modernidade: geopolítica brasileira. Rio de Janeiro: Bibliex, 2002.

PARAQUETT, Márcia. Questões imprescindíveis à formação de professores interculturais latinoamericanos: o lugar da cultura de tradição oral e afrodescendente. In: MATOS, Doris; PARAQUETT, Márcia (orgs.). Interculturalidade e identidades: formação de professores de espanhol. Salvador: EDUFBA, 2018. p. 73-99.

QUESADA, Sebastián. Imágenes de América Latina. Madri: Edelsa, 2001.

RAFFESTIN, Claude. Por uma geografia do poder. São Paulo: Ática, 1993.

RAJAGOPALAN, Kanavillil. O ensino de línguas estrangeiras como uma 
questão política. In: MOTA, Kátia; SCHEYERL, Denise (orgs.). Espaços linguísticos: resistências e expansões. Salvador, EDUFBA, 2009. p. 57-82.

RODRIGUES, Fernanda dos Santos Castelano. Língua viva, letra morta: obrigatoriedade e ensino de espanhol no arquivo jurídico e legislativo brasileiro. Tese (Doutorado em Letras). Universidade de São Paulo, São Paulo, 2010.

SALOMÃO, Ana Cristina Biondo. O componente cultural no ensino e aprendizagem de línguas: desenvolvimento histórico e perspectivas na contemporaneidade. Trabalhos em Linguística Aplicada, vol. 54, n. 2, p. 361-392, 2015. Disponível em: http://dx.doi.org/10.1590/010318134500150051. Acesso em: 26 jan. 2020.

SANTOS, M. A natureza do espaço. São Paulo: Edusp, 2006.

SARMIENTO, Domingo Faustino. Facundo. Buenos Aires: Biblioteca Argentina, 1921.

SERRANI, Silvana. Discurso e cultura na aula de língua. Campinas: Pontes, 2005.

UNESCO. Investir na diversidade cultural e no diálogo intercultural. Relatório Mundial da UNESCO.2009. Disponível em: http://www.dhnet.org.br/dados/relatorio s/r_edh/relatorio_unesco_cultura.pdf. Acesso em: 15 jun. 2020.

WENDT, Alexander. Social theory of international politics. Cambridge: Cambridge University Press, 1999. 